\title{
Modeling of the surface coverage and application to the calculation of friction on surfaces contaminated by particles
}

\author{
Y. Hichri, V. Cerezo, M. T. Do* \\ IFSTTAR, AME-EASE, 44344 Bouguenais, France.
}

\author{
* Corresponding author \\ Address: IFSTTAR, Allée des Ponts et Chaussées, CS5004, 44344, Bouguenais Cedex \\ Email: $\underline{\text { minh-tan.do@ifsttar.fr }}$
}

\begin{abstract}
This paper deals with the modeling of the coverage of surfaces contaminated by fine particles, the objective being the prediction of the skid resistance of road surfaces when it rains after a long dry period. The research methodology is based on the identification of particles' flows in the tribological circuit composed of the particles (3rd body) and the tire and the road (1st bodies). Experiments are conducted in laboratory where sliding friction is measured between a rubber pad (simulating a tire tread block) and a sandblasted aluminum surface (simulating a microtextured road surface) covered by particles. The test program includes particle concentrations representative of deposits of particles on the road surface at different dry periods and different particle size fractions. The test protocol consists in repeating passages of a rubber pad on the test surface and visualizing the particles' movements by means of high-speed cameras. Two particles' flows are identified: particles ejected from the contact and those raised by the rubber pad then fall back to the surface. Similarities are established with the removal and deposition of gas species in vapor-phase lubrication. An analytical model was derived to express the surface coverage as a function of the number of passages and two parameters (values between 0 and 1) called respectively the ejection and recirculation ratios. The proposed model is included in a linear rule-of-mixtures equation for the calculation of friction. Calculated friction coefficients compare favorably to experimental data and the model's parameters are determined. A master curve for different particles' sizes is obtained when relating the surface coverage to the mass of particles. Relationships between the ejection and recirculation ratios, the particles' characteristics and the surface texture are presented. Discussions are made in terms of transposition of the model to real road surfaces.
\end{abstract}


Keywords: particles; surface coverage; third body flow; friction.

\section{Introduction}

The increase of traffic crashes at the first rain after a long dry period has been attributed to the presence on the road surface of particles of diverse origins (dust, debris from tires, road surface and equipment, etc.) [1]. In a previous paper [2], laboratory tests were conducted to investigate the friction on dry contaminated road, in particular the effect of particles' characteristics (concentration, size) and the mechanism of trapping of the particles by the road surface texture. A model was proposed to represent the friction coefficient of a contaminated surface as a function of two friction coefficients for respectively unlubricated and fully lubricated conditions weighted by the surface fraction covered by the particles. The best fit of this model to experimental data was obtained when the surface coverage is expressed as the ratio of the mass of available particles to the total mass of particles raised to an exponent (n). Despite satisfactory comparisons between the theory and the experiments, no statistically significant link has been found between (n) and parameters related to the particles' characteristics or surface roughness.

This paper presents the work that has been continued on the modeling of the surface coverage and its application to the calculation of friction. To provide a physical meaning to the developed model, efforts have been focused on a better understanding of the movement of the particles at the tire/road interface. To achieve this goal, high-speed cameras were deployed to visualize the contact and the interpretation of the results was based on third-body flows in the tribological circuit composed of the tire and the road as the first bodies and the particles as the third body.

\section{Background}

In [2], the following model was proposed, inspired from works of Higgs and coauthors on $\mathrm{MoS}_{2}$ powder transfer films [3], to express the friction of surfaces contaminated by dry particles:

$$
\mu=X \cdot \mu_{\text {film }}+(1-X) \cdot \mu_{\text {surface }}
$$

Where $\mathrm{X}$ is the fraction of the surface covered by the particles, also called the surface coverage fraction; $\mu_{\text {surface }}$ and $\mu_{\text {film }}$ are the friction coefficients obtained when the surface is respectively clean and fully covered by particles.

Equation (1) expresses the fact particle lubrication can be considered, as previously stated in [3][4] for 
powder, as a mixed lubrication in which the applied load is supported by the asperity contact (for the general case of the contact between two rough surfaces) and the particle layer. In a mixed lubrication theory with a liquid lubricant, the load (or pressure) is used in place of the friction coefficient in equation (1) and the weighting factor $\mathrm{X}$ is expressed as the ratio of the load (or pressure) supported by the lubricant film [5]. The load (or pressure) components are then deduced, as in [6], from contact models such as Greenwood-Williamson's one [7] for the asperity contact and Reynold's equation for the lubricant film.

Another approach, as adopted in the present paper, uses the surface coverage to separate the bare and lubricant-covered part of the surface. As mentioned in [2], $\mu_{\text {surface }}$ and $\mu_{\text {film }}$ include mechanisms like rubber's hysteresis (dissipated energy) and adhesion (molecular bonds) for the first term, and shearing of particulate layers for the second. These mechanisms are complex as illustrated by works of Grosch [8] and Persson [9] for rubber friction and Mills [10] and Heshmat [4] for friction induced by transfer films. Modeling the terms $\mu_{\text {surface }}$ and $\mu_{\text {film }}$ deserves a separate work and is beyond the objective of this study. In the rest of the paper, discussions are focused on the determination of the surface coverage.

In [3], the surface coverage fraction is represented by:

$$
X=\frac{h}{h_{\max }}
$$

Where $\mathrm{h}$ is the thickness of the layer of available particles; and $\mathrm{h}_{\max }$ is the thickness of the layer of particles that cover completely the surface.

In [2], the first attempt was deriving $h$ and $h_{\max }$ from 3D topographical maps measured on contaminated surfaces. It was found that this approach can induce some unexpected results, such as $\mathrm{h}>\mathrm{h}_{\max }$, due to the formation of clumps of particles on the top of the surface asperities. The so-called index of starvation was then used to characterize the surface coverage fraction. In his original work on powder lubrication [4], Heshmat defined the index of starvation as the ratio between the amount of powder available and the amount of initial powder (continuous film). Based on similarities between Heshmat's work and [2], in terms of contact conditions (first bodies separated by a particulate third body) and the observed relationship between the friction coefficient and the mass of the third body, the surface coverage was defined in [2] as:

$$
X=I_{\text {starvation }}^{n}=\left(\frac{m_{\text {particles }}^{\text {available }}}{m_{\text {particles }}^{\text {total }}}\right)^{n}
$$

Where $I_{\text {starvation }}$ is the index of starvation; mparticles is the mass of particles present on the surface; $m_{\text {particles }}^{\text {total }}$ is the total mass of particles (corresponding to the chosen initial concentration); and $\mathrm{n}$ is an exponent 
to be determined.

As explained in the introduction, this approach is not satisfactory yet due to the lack of physical meaning of exponent $\mathrm{n}$. Research of the literature has shown that most of the past works dealing with the surface coverage were related to the wear of surface coatings or the process of gas adsorption. Blanchet and Sawyer [11] studied the wear of thin solid films and used the Archard law to derive an analytical model expressing the film fractional coverage as a function of the position within the contact region (in a pin-on-disc experiment, the coverage decreases because of the removal of the surface film by the pin). This model assumes that debris detached from the film are ejected from the contact and do not provide lubrication as third bodies. Sawyer and Dickrell [12] extended this work to take into account another phenomenon when the tribosystem (pin-on-coated disc for example) operates in a gaseous environment which is the adsorption. Actually, gas species can deposit on a surface due to a direct chemical bond or intermolecular forces between the surface and the gas molecules (adsorbate); this deposition process can induce the so-called vapor-phase lubrication. Sawyer and Dickrell used works of Langmuir [13] to express the surface coverage due to gas deposition as a function of the pressure of the gas, the time of exposure and a deposition constant. Dickrell and coauthors [14] finally derived a model combining the removal and deposition processes of gas species, using results from respectively [11] and [13], on an initially bare surface and predict the evolution of the pin/disc friction coefficient with the number of pin (or disc) rotations. The model was successfully compared to experimental results from [15]. The approach developed in [14] seems to be promising with respect to the aim of the present study.

\section{Research methodology}

To transpose the models developed for vapor-phase lubrication, it is necessary to draw a parallel between the removal and deposition processes and the particles' movements. The idea is to consider the tribological circuit composed of the tire and the road as first bodies and the particles as third bodies and identify particles' flows among the following six flows cited in [16] (Figure 1): 1- external source $Q_{S}^{e}$ composed of artificially introduced third body; 2- internal source $Q_{s}^{i}$ composed of detached particles (natural third body); 3- internal flow $Q_{i}$ of third bodies in the contact; 4- external flow $Q_{e}$ of ejected third bodies; 5- recirculation flow $Q_{r}$ composed of third bodies ejected and reintroduced in the contact; and 6- wear flow $Q_{w}$ composed of third bodies definitely ejected. 


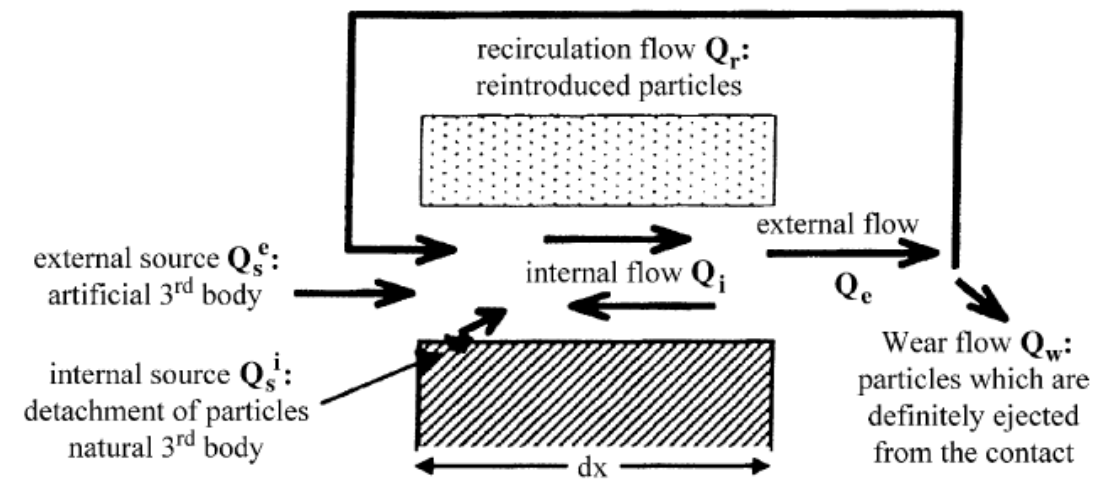

Fig.1 Tribological circuit and third-bodies flows (from [16])

In [2][17], two particles movements were identified from the analysis of the mass of particles and SEM pictures: there are particles ejected from the contact and those trapped by the road surface microtexture (surface irregularities with dimensions lower than $0.5 \mathrm{~mm}$ horizontally and vertically). These movements could be assimilated to flows $Q_{w}$ and $Q_{i}$ respectively. This analysis was done from a global (mass) and static (SEM) approach and there is a need to complete this work by using other methods enabling a dynamic and local visualization of the contact. Friction tests were then conducted following the protocol defined in [2] (section 4.3). A test set-up was developed to visualize the tests by means of high-speed cameras (section 4.4). From the particles' flows identified by visualizations (section 5), an analytical model was written to describe the surface coverage (section 6.1). As there is no mean to measure directly the surface coverage, the proposed model was included in equation (1) and validation, as well as calibration of the model parameters, was done via the comparison of calculated and measured friction coefficients.

\section{Experiments}

\subsection{Samples}

Road surfaces are conventionally composed of two texture scales: the macrotexture (surface irregularities with dimensions ranging from 0.1-20 $\mathrm{mm}$ vertically and $0.5-50 \mathrm{~mm}$ horizontally) and the microtexture (surface irregularities with dimensions lower than $0.5 \mathrm{~mm}$ horizontally and vertically). Preliminary tests with high-speed cameras (close-up view, see section 3.4) showed that the visualization of particles' movements is not feasible with such surface topography (incompatibility between the size of the particles to be observed and the variation of the surface heights). Moreover, it was stated in [18] that the dust and debris that have settled on the road affect mainly the microtexture of the road surface. Model surfaces with only the microtexture are then sought to reduce 
the amplitude of the surface heights, thus facilitating the visualization, without compromising the studied phenomenon.

The test sample is an aluminum rectangular slab of $130 \mathrm{~mm} \times 80 \mathrm{~mm} \times 15 \mathrm{~mm}$ (Figure $2 \mathrm{a}$ ). The choice of aluminum to represent a road surface can seem to be surprising. Actually, the test protocol requires weighing of the test sample before and after friction measurements to determine the mass of particles (results are reported in [2]) and road samples are too heavy for the precision scale used in the study. Moreover, as the study is primarily focused on mechanical interactions (void filling, rolling / sliding, etc.) between the particles and the road surface asperities, emphasis is given first to the reproduction of the surface microtexture.

a)

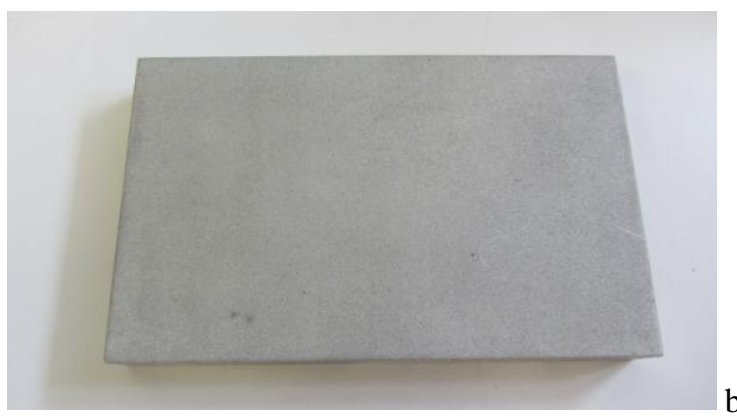

b)

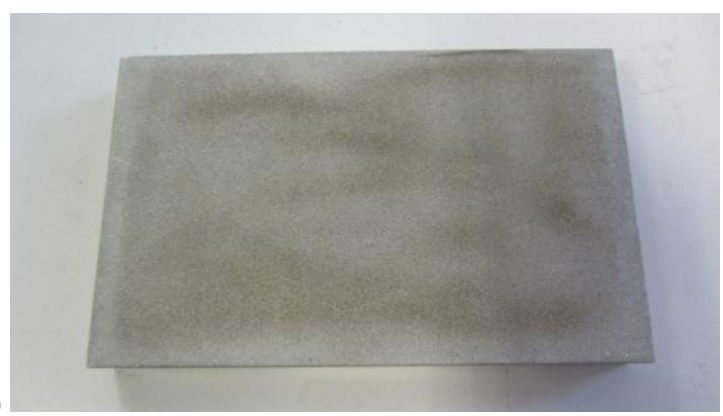

Fig.2 Test sample: a) clean; b) covered by particles

The sample surface is sandblasted using a nozzle projecting corundum particles of diameter smaller than 2 $\mathrm{mm}$. Values of roughness parameters in Table 1 (mean value of three topographical maps of $5 \mathrm{~mm} \times 5 \mathrm{~mm}$ measured by means of an InfiniteFocus ${ }^{\circledR}$ sensor developed by Alicona and working on the principle of focus variation [19]) show that this treatment reproduces a microtexture similar to that of a polished road aggregate. The volume parameters are derived from the Abbott curve using $10 \%$ and $80 \%$ as default values of the heights for the boundaries among the valley section, core section, and peak section.

Tab.1 Texture characteristics of the test sample

\begin{tabular}{ccc}
\hline Parameters & Test sample & $\begin{array}{c}\text { Polished } \\
\text { aggregate }\end{array}$ \\
\hline $\begin{array}{c}\mathrm{S}_{\mathrm{q}} \\
(\mu \mathrm{m})\end{array}$ & 13.9 & 16.8 \\
$\begin{array}{c}\text { (root mean squared } \\
\text { height) }\end{array}$ & & \\
\hline
\end{tabular}




\begin{tabular}{|c|c|c|}
\hline $\begin{array}{c}\mathrm{V}_{\mathrm{mp}} \\
\left(\mathrm{ml} / \mathrm{m}^{2}\right) \\
\text { (material volume of } \\
\text { the peak section) }\end{array}$ & 0.604 & 0.702 \\
\hline $\begin{array}{c}\mathrm{V}_{\mathrm{mc}} \\
\left(\mathrm{ml} / \mathrm{m}^{2}\right) \\
\text { (material volume of } \\
\text { the core section) }\end{array}$ & 12.3 & 12.8 \\
\hline $\begin{array}{c}\mathrm{V}_{\mathrm{vc}} \\
\left(\mathrm{ml} / \mathrm{m}^{2}\right) \\
\text { (void volume of the } \\
\text { core section) }\end{array}$ & 15.7 & 17.9 \\
\hline $\begin{array}{c}\mathrm{V}_{\mathrm{vv}} \\
\left(\mathrm{ml} / \mathrm{m}^{2}\right) \\
\text { (void volume of the } \\
\text { valley section) }\end{array}$ & 1.82 & 2.38 \\
\hline
\end{tabular}

\subsection{Particles}

Sediments transported by runoff water from the South part of the Cheviré bridge $(1.5 \mathrm{~km}$ long, crossing the Loire river in Nantes and supporting a daily traffic of 90,000 vehicles with $8.5 \%$ of trucks) were collected from a catchment area near the bridge. They are then oven-dried in laboratory $\left(40^{\circ} \mathrm{C}\right.$ during 4 days) and sieved to obtain four size fractions: $0-40 \mu \mathrm{m}, 40-50 \mu \mathrm{m}, 50-80 \mu \mathrm{m}$, and $80-100 \mu \mathrm{m}$. This method to collect particles was preferred to the vacuuming-based techniques because the latter provide too small quantities of particles (some milligrams).

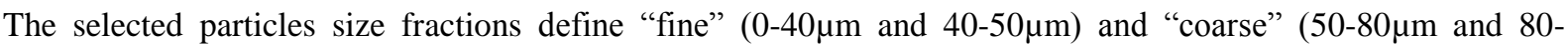
$100 \mu \mathrm{m})$ fractions. The limit value of $50 \mu \mathrm{m}$ was defined in [10] as the point at which the lubrication mechanism induced by a particle layer can switch from a sliding / shearing action to a shearing / rolling action.

Chemical analysis (detailed in [17]) shows that the particles are mainly composed of Si (68\%) which is a hard mineral. The other elements are: $\mathrm{Na}(3.5 \%), \mathrm{K}(4 \%)$ and $\mathrm{Mg}(1.5 \%)$ whose presence can be explained by industrial sites located next to the Cheviré bridge; metallic components such as $\mathrm{Al}(12 \%)$ and $\mathrm{Fe}(6 \%)$ whose presence can be attributed to the wear of braking system and tires; and other elements in insignificant amounts [17]. It was shown in [2] that the chemical composition of the particles extracted from sediments is similar to that of particles collected directly from the road surface. The density of the particles is determined from measurements defined by standard EN 1097-7 [20]. The values obtained for the four size fractions are respectively $2530,2550,2670$ and $2570 \mathrm{~kg} / \mathrm{m} 3$, giving a mean value of $2580 \mathrm{~kg} / \mathrm{m} 3$ and a coefficient of variation (ratio standard deviation / mean) of $2.4 \%$; the mean value is therefore adopted for all size fractions.

Three quantities of dry particles are used, expressed in terms of concentration: $10 \mathrm{~g} / \mathrm{m}^{2}, 20 \mathrm{~g} / \mathrm{m}^{2}$ and $40 \mathrm{~g} / \mathrm{m}^{2}$. Based on data from [21], these concentrations represent the expected deposit after respectively 2, 4 and 7 dry 
days on a high traffic road. Particles are spread manually on the slabs and then compacted by means of a metallic wheel enveloped by a rubber band (Figure 3a). The vertical load applied to the test surface is due only to the weight of the wheel $(6.5 \mathrm{~kg})$. From the footprint between the wheel and the test surface (Figure $3 \mathrm{~b}$ ) (measured with a two-sheet type Ultra Super Low Pressure Fujifilm LLLW), the mean contact pressure is estimated to be $0.16 \mathrm{MPa}(6.5 \times 9.81 /(5 \times 80))$, which is close to the pressure between a light vehicle tire and a road surface (0.20MPa). Sixty repeated passes (30 back and forth) are performed to obtain a homogenous distribution of the particles on the test surface (Figure 2b).

a)
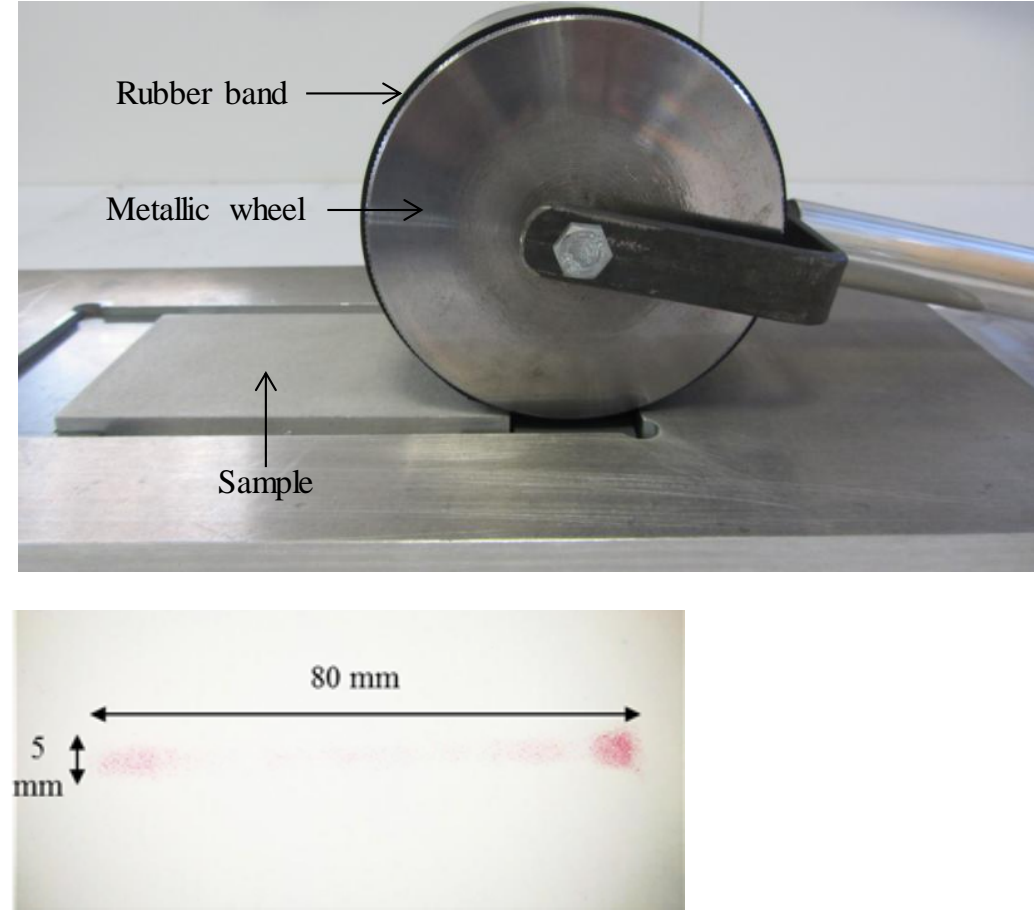

Fig.3 Wheel used for the compaction of deposited particles: a) view of the set-up; b) footprint measured by a Fujifilm (the absence of color in the center of the footprint is probably due to the actual pressure which is slightly lower than the measuring range of the film $0.20-0.60 \mathrm{MPa}$ )

\subsection{Friction measurement}

Friction is measured by means of a Skid Resistance Tester (SRT) Pendulum (Figure 4), which is widely used to assess skid resistance of diverse surfaces such as pavements, pedestrian crossings, industrial floors, etc. The test protocol consists in repeating passages of the rubber pad mounted at the end of the pendulum's articulated arm (Figure 4) on the test surface. The test surface is covered once and there is no addition of particles between the passages. The friction coefficient is recorded after each passage and the sample is weighed before and after each passage (Sartorius Cubis ${ }^{\circledR}$ scale with a reading precision of $0.001 \mathrm{~g}$ ). A test series is defined as a series of 
steps, each corresponding to a state of contamination of the surface: step 0 is the clean surface; step 1 is the surface initially covered by particles; step 2 is the surface after one passage; and so on. Measurements are stopped when three successive values of the friction coefficient do not differ more than 0.01 .

The rubber pad is provided by the Pendulum builder and made of rubber with hardness (IRHD) of 55. It dimensions are $76.2 \mathrm{~mm}$ wide, $25.4 \mathrm{~mm}$ long and $6.35 \mathrm{~mm}$ thick. As the friction loss due to particles occurs at low slip speeds (less than $16 \mathrm{~km} / \mathrm{h}$ ) [18], tire grooves have a negligible effect and the use of a rubber block with no groove to simulate the tire friction does not bias the studied phenomenon. The rubber pad is wiped by a soft cloth after each passage to remove particles that accumulate at the slider edge. At the end of a test series, the sample is cleaned first by compressed air then by water during 2 minutes in an ultrasound tub. It is dried during at least 2 hours at ambient temperature before the starting of another test series.

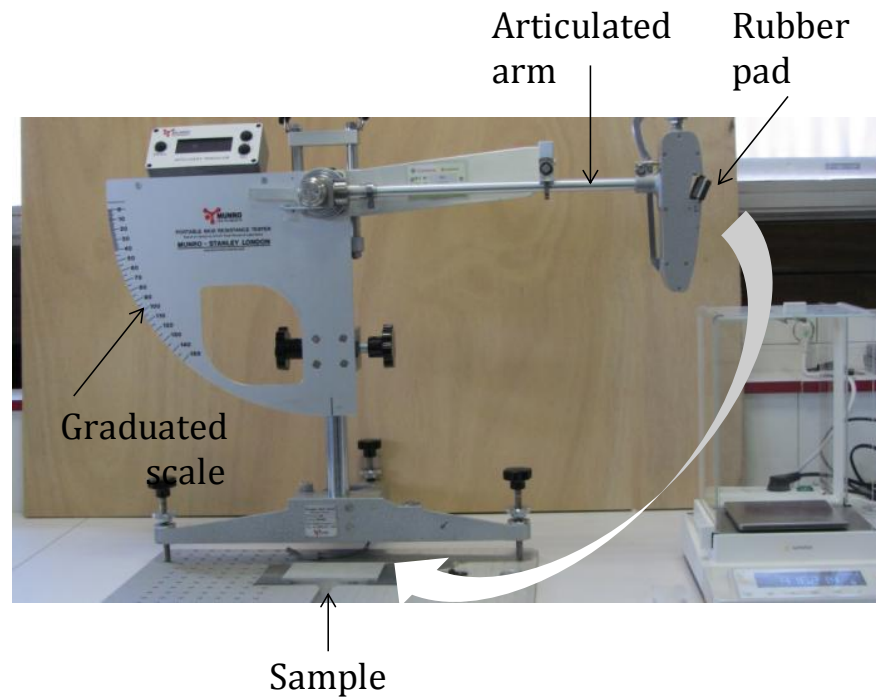

Fig.4 Skid Resistance Tester Pendulum (on the right, the Sartorius Cubis scale used for weighing the sample)

\subsection{Observations of particles' flows}

Two cameras were used to visualize particles' movements during a passage of the SRT pad. The test set-up is shown in Figure 5. A GoPro camera (HERO5) was first used to record (240 frames per second) a wide field view when the pad slides on the test surface. A high-speed camera (Motion BLITZ Cube4 with a lens Sigma 105mm 1:2.8 DG MACRO) was then used to record (6000 frames per second) a close-up view of the contact (30mm in the center part of the sliding distance $-126 \mathrm{~mm}$ - of the pad). Calibration tests [17] showed that the size of a pixel is $12 \mu \mathrm{m} \times 12 \mu \mathrm{m}$. This information enables to measure the distance travelled by particles and their speed 
knowing the time slot between two frames.

a)

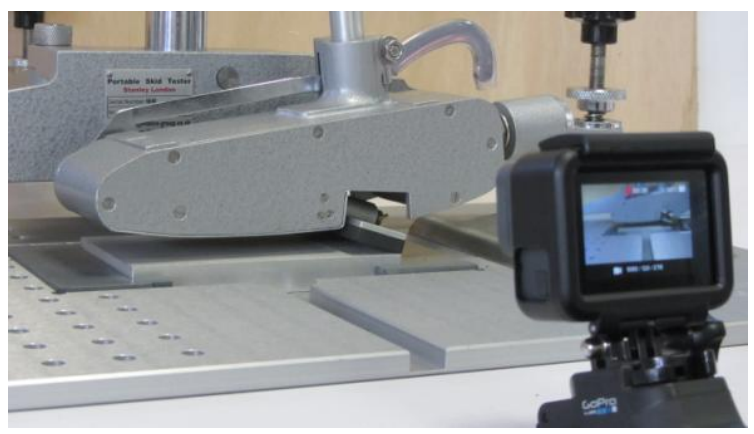

b)

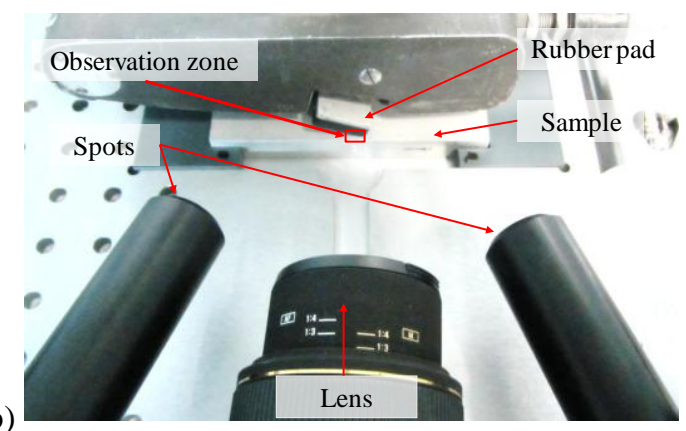

Fig.5 Set-up for the observation of particles' flows: a) with the GoPro camera; b) with the high-speed camera

\section{Results from the visual observations}

\subsection{Wide field views}

Images extracted from a video recorded by the GoPro camera are presented in Figure 6. It can be seen that the sliding movement of the rubber pad induces an uplift of the particles, which can be divided into two parts: one is ejected from sample and the other falls back to the sample surface.

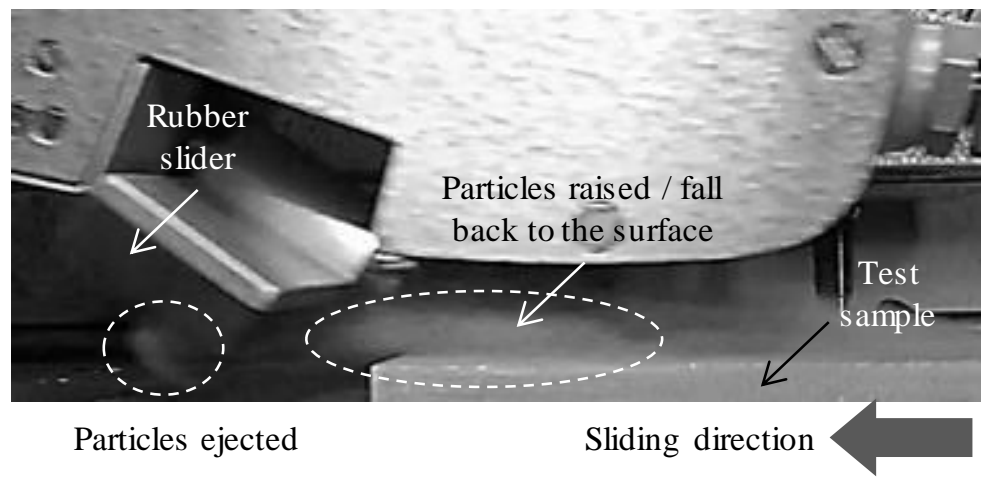

Fig.6 Particles' flows viewed by the GoPro camera (fraction: $40-50 \mu \mathrm{m} ; 1^{\text {st }}$ passage of the SRT pad)

Figure 7 shows pictures extracted from the videos of the first three passages of the SRT pad for fine (Figure 7 a) and coarse (Figure 7b) particles. It can be seen that the particle cloud (located by the arrows) decreases with the number of passages. For fraction $80-100 \mu \mathrm{m}$, the decrease is rapid and the clouds are barely visible from the second passage. 

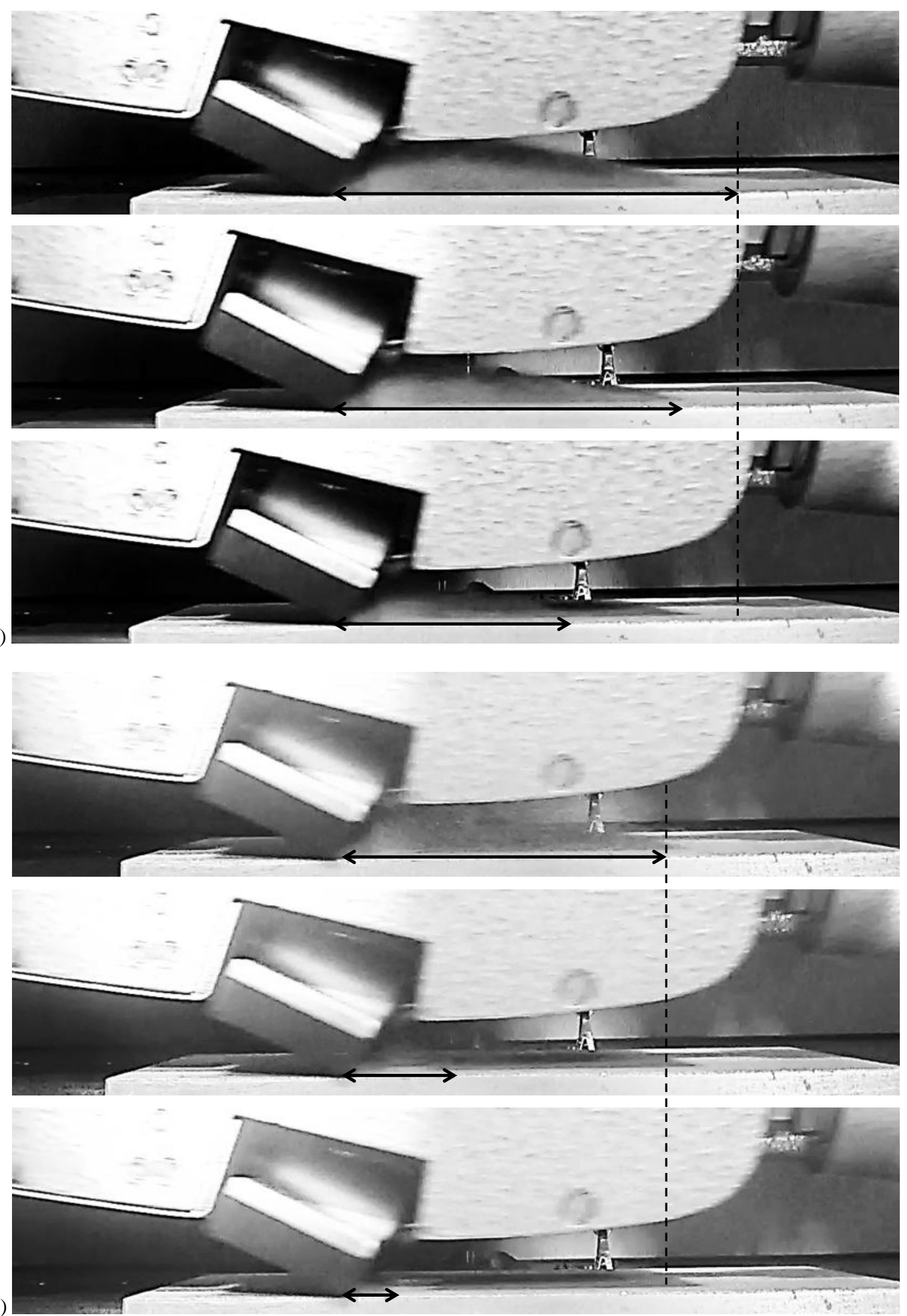

Fig.7 Evolution of particles' flows at $1^{\text {st }} 2^{\text {nd }}$ and $3^{\text {rd }}$ passages: a) fraction $40-50 \mu \mathrm{m}$; b) fraction $80-100 \mu \mathrm{m}$ (the arrows provide an idea about the length of the particles' cloud; the dotted line shows the decrease of the particles' clouds) 


\subsection{Close-up views}

A closer view of the sliding movement of the SRT pad is presented in Figure 8. In addition to the particle cloud, some rubber debris can be seen as well. These debris come probably from the wear of the SRT pad. Weighing of the slider shows that its mass loss during a test series is negligible (few milligrams) compared with the mass of introduced particles (hundreds of milligrams). For this reason, the rubber debris will not be considered in the analyses.

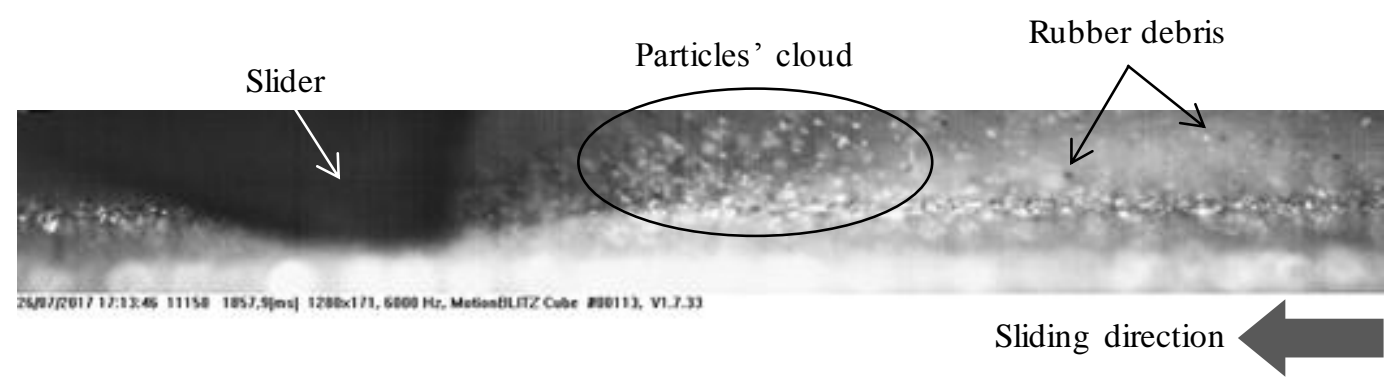

Fig.8 Particles' flows viewed by the high-speed camera (Particles' fraction: $40-50 \mu \mathrm{m} ; 1^{\text {st }}$ passage of the SRT pad)

In figure 9a, the particle clouds for different particles' size fractions are shown. With fractions $0-40 \mu \mathrm{m}$ and

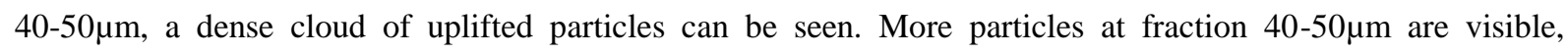
probably due to fact that part of the particles at fraction $0-40 \mu \mathrm{m}$ is trapped by the surface texture. With fractions $50-80 \mu \mathrm{m}$ and $80-100 \mu \mathrm{m}$, the cloud of particles is less dense. After Changarnier and coauthors [17], as quartz (predominant element in the composition of the particles) and aluminum are harder than rubber, the slider is the most deformed in the interaction slider / particles / substrate. Just as the particles leave the interface between the slider and the substrate, the slider recovers its initial geometry and there is a pinching effect that throws the particles up a few millimeters behind the slider; once in the air, the particles either settle on the substrate or are entrained by the air flow and leave the substrate. 

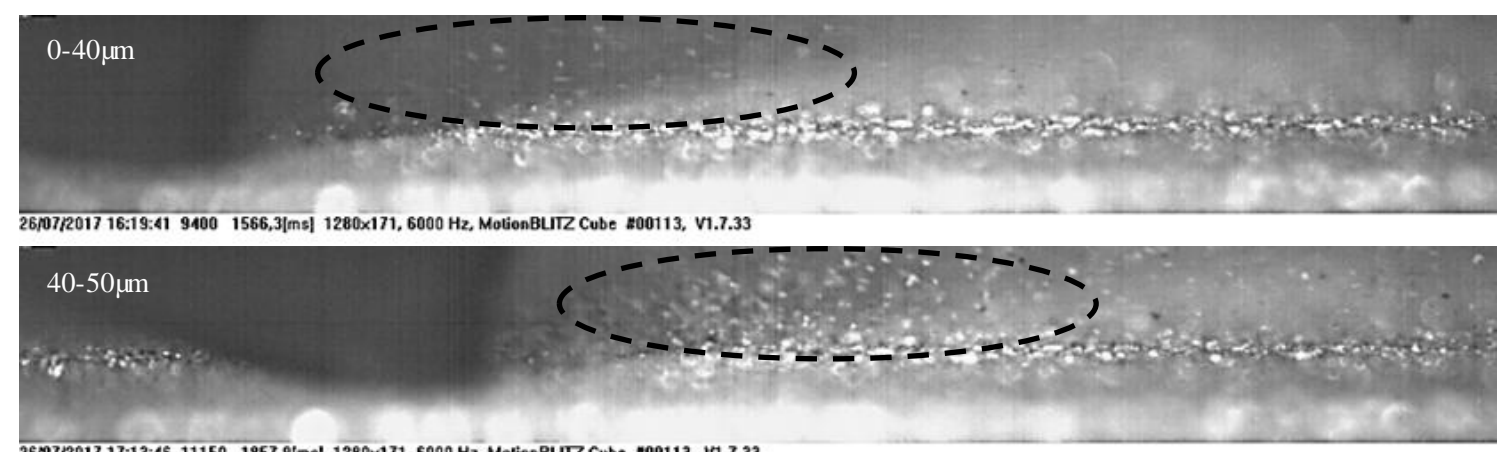

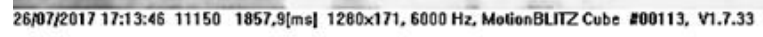
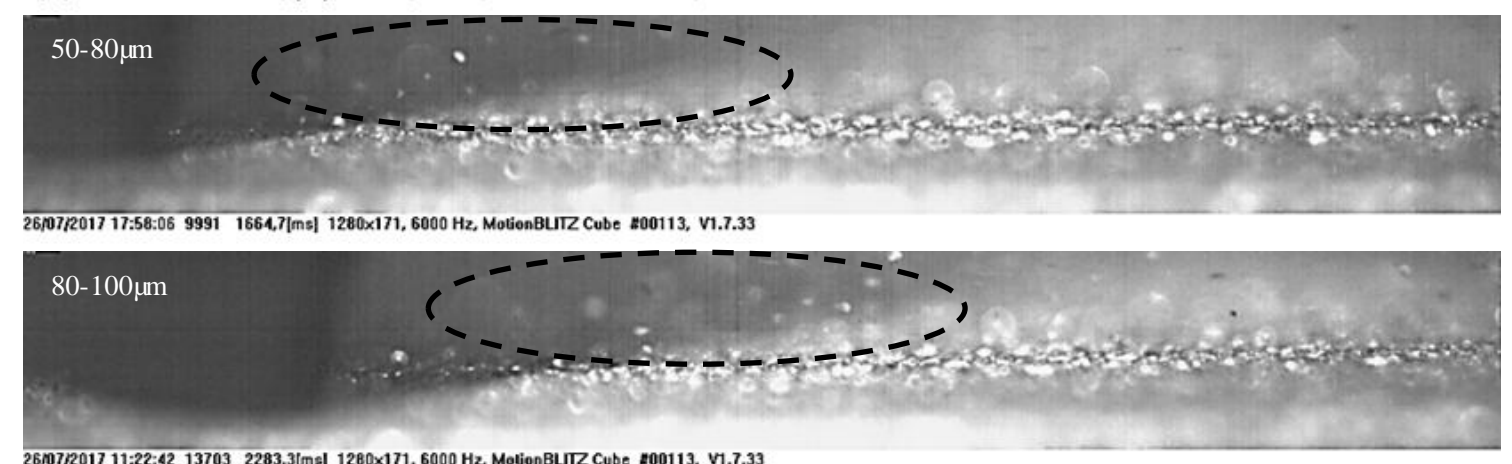

a)
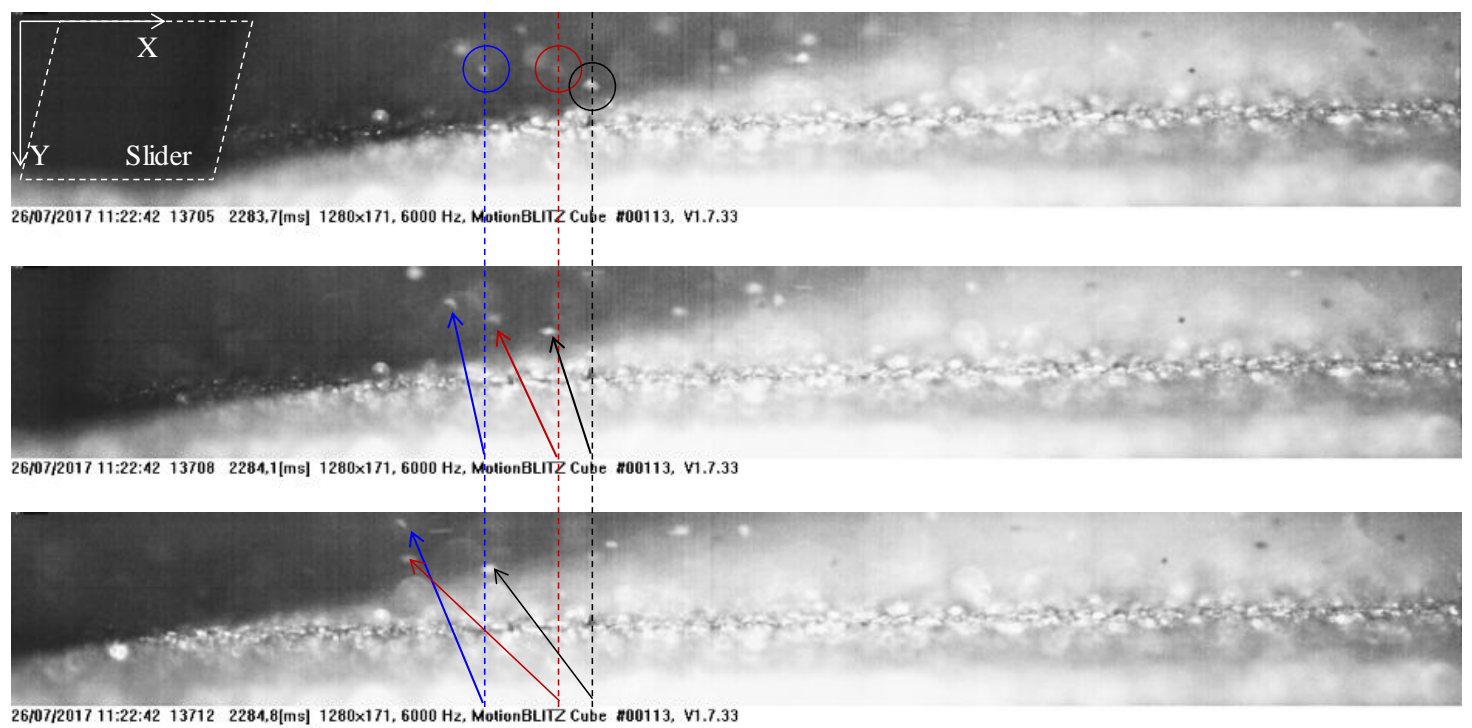

b)

$15360 \mu \mathrm{m}(1280$ pixels $)$

Fig.9 Particles' flows viewed by the high-speed camera: a) Particles' clouds (dotted ellipses) for different size fractions; b) Tracking of three particles (the dotted line corresponds to the position of the studied particle in the first image; the arrows show not only the position of the same particle in the following images, relative to its position in the first image, but also the trajectory and the speed)

Efforts were made to track three particles for each size fractions and, knowing the time slot between two images extracted from the videos, it was possible to plot their trajectories and estimate their speed. The selection of the particles depends on their position (between $2 \mathrm{~mm}$ and $3.36 \mathrm{~mm}$ from the rear edge of the slider), their spacing (to ensure that the estimated speed is representative of the cloud) and the possibility to track them on at 
least 5 successive frames (with a maximum of 10 frames). The free-on-line software GIMP (GNU Image Manipulation Program) had been used for the analyses. The trajectories are illustrated in Figure $9 \mathrm{~b}$ by the arrows, which show not only the position of a particle in the images, relative to its position in the first image, but also the trajectory and the speed (because the speed is calculated from the position and the elapsed time).

The estimated speed is the product (number of pixels separating the position of a particle between two given frames $\times 12 \mu \mathrm{m}$ ) divided by the elapsed time between the two frames. It is calculated in $\mathrm{X}$ and $\mathrm{Y}$ directions, giving respectively speed components $\mathrm{V}_{\mathrm{x}}$ and $\mathrm{V}_{\mathrm{y}}$, and the speed reported is: $V=\sqrt{V_{x}^{2}+V_{y}^{2}}$. The estimated speeds for each particle, as well as their mean values, are presented in Table 2. Despite some scatters between the individual speeds, it can be seen that, in average, the speed of the particles varies with their sizes: the smaller is the particle size, the lower is their speed.

Tab.2 Speed of the particles raised by the passage of the rubber pad

\begin{tabular}{lcccc}
\hline \multicolumn{1}{c}{ Particle speed $(\mathbf{m} / \mathbf{s})$} & $\mathbf{0 - 4 0}$ & $\mathbf{4 0 - 5 0}$ & $\mathbf{5 0 - 8 0}$ & $\mathbf{8 0 - 1 0 0}$ \\
\hline Particle 1 & 0.64 & 0.83 & 0.75 & 0.88 \\
Particle 2 & 0.87 & 0.91 & 1.18 & 1.42 \\
Particle 3 & 0.34 & 0.84 & 1.56 & 0.92 \\
Mean & $\mathbf{0 . 6 2}$ & $\mathbf{0 . 8 6}$ & $\mathbf{1 . 1 6}$ & $\mathbf{1 . 0 7}$ \\
Standard deviation/mean & $43 \%$ & $5 \%$ & $35 \%$ & $28 \%$ \\
\hline
\end{tabular}

\subsection{Interpretation in terms of particles' flows}

Observations by means of high-speed cameras have revealed three flows of the particles in the contact zone:

- The detachment flow composed of rubber debris from the SRT pad. Due to the significant difference between aluminum and rubber in terms of deformation, there should be no material detachment from the sample.

- $\quad$ The ejection flow, which represents the particles aspired behind the pad and ejected from the contact.

- The recirculation flow, which represents the particles that are raised and fall back onto the surface as well as the particles that remain trapped by the texture.

The third flow is a new element provided by dynamic visualizations. If one neglects the detachment flow (as explained in 5.2), it can be said that the following flows occur inside the tribological circuit tire/particles/road: an external source $Q_{s}^{e}$ composed of deposited particles and an external flow $Q_{e}$ of ejected particles. The latter flow can be divided in turn into: 1- a recirculation flow $Q_{r}$ composed of trapped particles and particles raised and fall 
back to the road surface; and 2- a wear flow $Q_{w}$ composed of particles definitely ejected. One can expect that an internal flow also occurs due to, for example, rolling of particles under the SRT pad; at the moment, there is no experimental evidence to confirm the existence of this flow.

In [2] and [22], it was thought that the passage of the SRT pad induces a shear in the particle layer that thins to the point where the rubber-surface asperity contact is established; during this shearing process, the particles are either ejected from the contact or trapped by the surface texture. This reasoning induces in turn the idea following which the surface coverage should decrease continuously with the repetition of the passages of the rubber pad and can be modelled by, for example, an approach based on a removal process as developed in [11]. The existence of a recirculation flow requires another approach that considers two processes: the removal process and the re-deposition process (the words "re-" are used because no new particle is introduced).

\section{Modeling of the surface coverage fraction}

\subsection{Development of the model}

In this section, a description of the model developed in [14] is first provided. Similarities between the adsorption and removal of gaseous contaminants and the flows of particles, as identified in section 5, are then presented. The transposition of the model of reference [14] to the present study is then detailed.

\subsubsection{The Dickrell's model for the adsorption and removal of gas species}

In [14], Dickrell and coauthors studied the frictional behavior of diamond-like carbon (DLC) films and developed a model to calculate the fractional coverage of the film surface by environmental contaminants (gas species) during a pin-on-disc test. The model considers a surface element during a rotation of the disc. After this element leaves the pin (Figure 10), it is exposed to the gaseous environment and a deposit occurs - by adsorption - on the surface during the time it takes to return to the contact. Under the pin contact, part of the deposit is removed (Figure 10). The surface coverage results then from the combination of these adsorption and removal mechanisms. Two parameters characterize respectively these mechanisms [14]: The adsorption ratio $\alpha$ is the fraction of the uncovered surface leaving the pin contact that becomes covered by gas contaminants; and the removal ratio $\lambda$ is the ratio of the fraction of the surface covered at the exit of the pin contact to that at the entrance. 


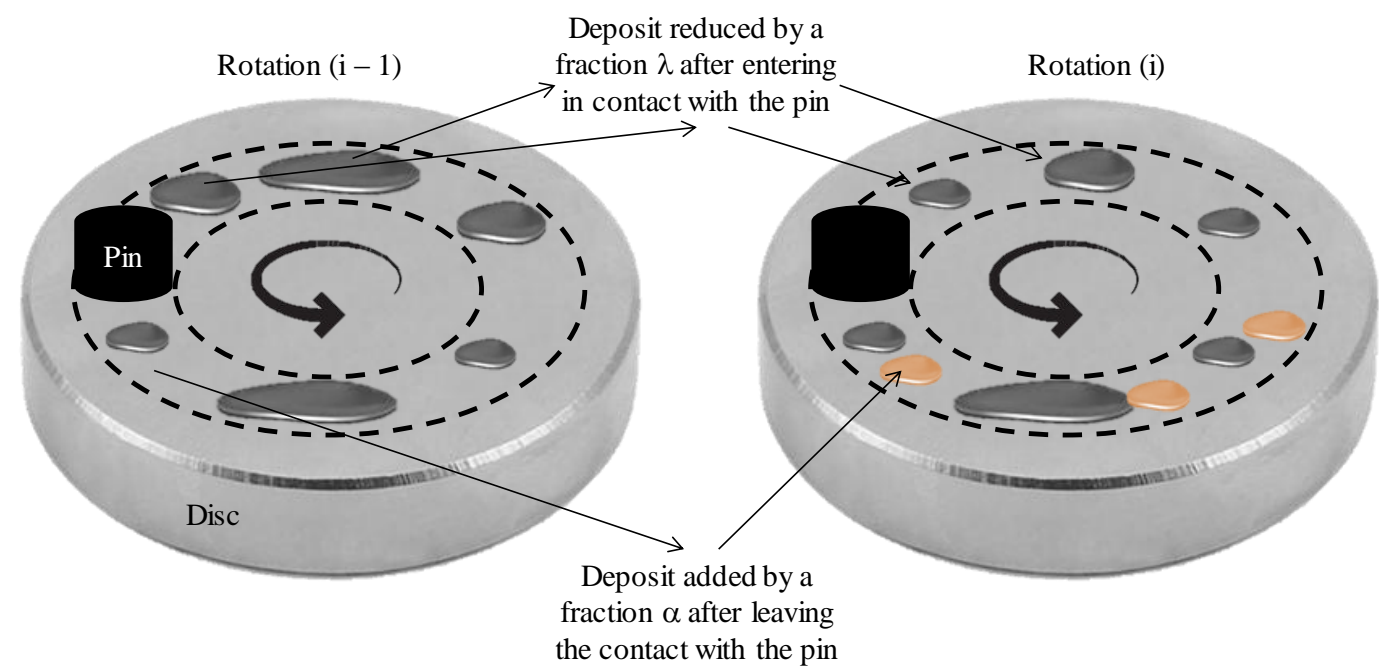

Fig.10 Illustration of the adsorption and removal of gas species modelled in [14]

The coverage fraction $X_{n}$ at the entrance of the pin contact at rotation $n$ is defined by [14]:

$$
X_{n}=X_{0}+\left(\sum_{k=1}^{n} \lambda^{(k-1)}(1-\alpha)^{(k-1)}\right)\left(\lambda X_{0}+\alpha-\lambda \alpha X_{0}-X_{0}\right)
$$

Where $\mathrm{X}_{0}$ is the initial coverage.

The sum term is equal to:

$$
\sum_{k=1}^{n} \lambda^{(k-1)}(1-\alpha)^{(k-1)}=\frac{1-(\lambda(1-\alpha))^{n}}{1-\lambda+\alpha \lambda}
$$

Introducing (5) into (4) gives:

$$
X_{n}=X_{0}(\lambda(1-\alpha))^{n}+\alpha\left(\frac{1-\lambda^{n}(1-\alpha)^{n}}{1-\lambda(1-\alpha)}\right)
$$

\subsubsection{Transposition of the Dickrell's model}

Despite differences between the studied phenomena, some similarities can be noticed between Dickrell's study and the present one:

- The disc (or pin if one considers the disc as fixed) rotations correspond to the passages of the SRT pad.

- The adsorption of gas species can be assimilated to the deposit of particles raised by the passage of the SRT pad and fall back to the surface. Ratio $\alpha$ can be renamed as a "recirculation ratio" as the raised 
particles are considered as ejected from the tribological circuit and, when they fall back to the surface, reintroduced into the contact.

- The removal of gas species corresponds to the ejection of particles by the SRT pad. Ratio $\lambda$ is renamed as "ejection ratio".

The surface coverage at step (i) can be then defined as:

$$
X_{i}=X_{1}(\lambda(1-\alpha))^{i-1}+\alpha\left(\frac{1-\lambda^{i-1}(1-\alpha)^{i-1}}{1-\lambda(1-\alpha)}\right)
$$

It can be noticed that the initial coverage is $X_{1}$ because state 0 corresponds to a clean surface. As a matter of fact, the exponent starts from (i - 1) and not from (i).

As there is no direct measurement of the surface coverage during a test series, Equation (7) cannot be compared to experimental data. It has first to be introduced into Equation (1) and the calculated friction coefficient is compared to measurements performed by the SRT device.

\subsection{Results}

Equation (1) is fully determined by five parameters: $\mu_{\text {film }}, \mu_{\text {surface }}, X_{1}, \alpha$ and $\lambda$. Parameters $X_{1}$ and $\mu_{\text {surface }}$ are first deduced from the experiments, i.e., $\mathrm{X}_{1}$ from the measured height cartographies and $\mu_{\text {surface }}$ from the friction coefficient measured on the bare surface. Despite many attempts using different quantities of particles, it was not possible to obtain in a repeatable way a uniform layer that fully covers the surface of the sample; it was then not possible to obtain $\mu_{\text {film }}$ by friction measurements. The friction coefficient calculated from (1) is then compared to the friction coefficient measured on contaminated surfaces, from which $\mu_{\text {film }}, \alpha$ and $\lambda$ are deduced.

\subsubsection{Determination of the initial coverage fraction $\mathrm{X}_{1}$}

As it is expected that the surface coverage depends on its topography, 3D height topographical maps (see 4.1) were used to determine the initial coverage fraction $\mathrm{X}_{1}$. Knowing the mass of the particles at step $1\left(\mathrm{~m}_{1}\right)$, the density of the particles $\rho$ and the surface of the sample $S$, an equivalent height of the film of particles $h_{1}$ is calculated by the following equation:

$$
h_{1}=\frac{m_{1}}{\rho . S}
$$

For the determination of the initial coverage fraction $\left(\mathrm{X}_{1}\right)$, it is assumed that particles are spread and fill all the voids of the test surface homogeneously. Using the MountainsMap® software, the method consists of 
thresholding the surface from the deepest point of the surface valleys to the estimated height $\mathrm{h}_{1}$ and calculating the filled void volume equivalent to this height (Figure 11). Knowing the total void volume of the surface (clean surface), $X_{1}$ is calculated from the following equation (see definitions of volumes $V_{v c}$ and $V_{v v}$ in section 4.1):

$$
X_{1}=\frac{\left(V_{v c}+V_{v v}\right)_{h 1}}{\left(V_{v c}+V_{v v}\right)_{\text {total }}}
$$

It can be seen from Figure 11 that $X_{1}$ is not equal to 1 , confirming visual observations following which the surface is not fully covered by the particles at the studied concentrations.

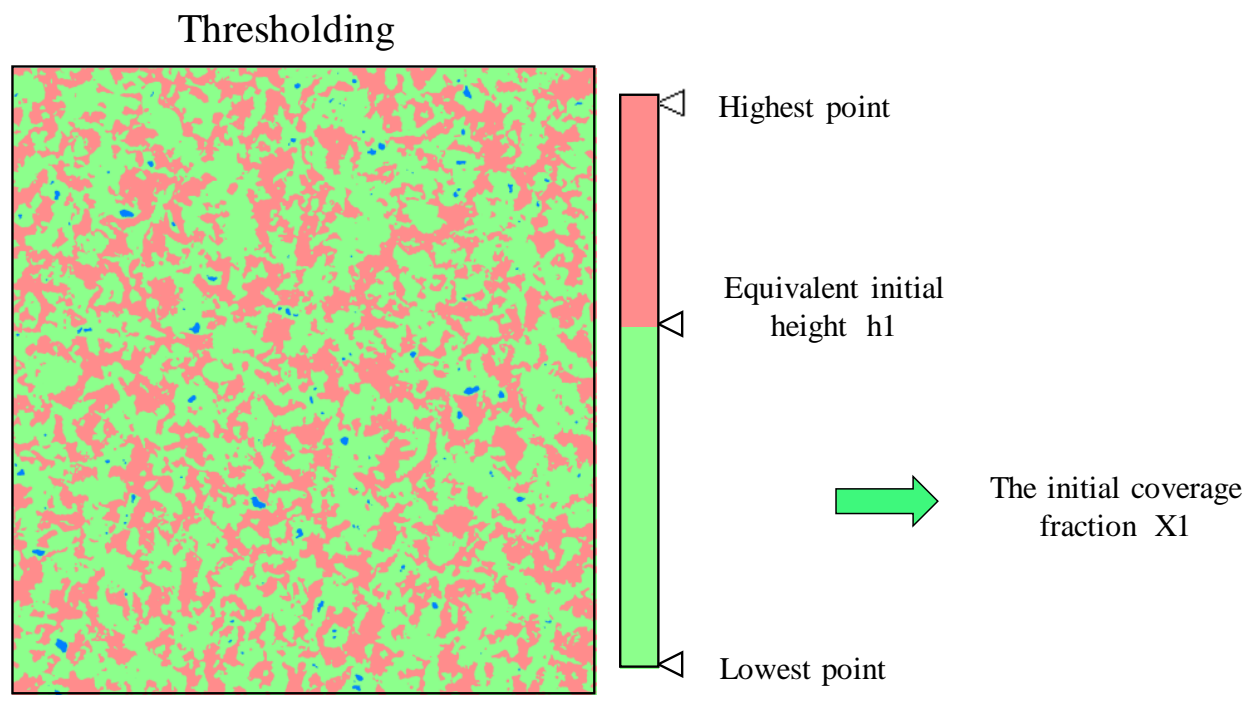

Fig.11 Determination of the initial surface coverage from height topographical maps

\subsubsection{Determination of $\mu_{\text {surface }}$ and $\mu_{\text {film }}$}

For the calculation of friction, $\mu_{\text {surface }}$ is obtained by averaging all measured friction coefficients at the clean condition (12 values for test series corresponding to 3 concentrations $\times 4$ sizes); a mean value of 1.11 is obtained with a standard deviation of 0.016 .

For $\mu_{\text {film }}$, the parameter was obtained by adjustment (see 6.2.3). In addition, it is assumed that $\mu_{\text {film }}$ does not depend on the particles' concentration and size; its value is then obtained by averaging the 12 values corresponding to 3 concentrations $\times 4$ sizes, giving $\mu_{\text {film }}=0.28$ with a standard deviation of 0.058 .

\subsubsection{Calculation of friction}

The comparison of calculated and measured friction coefficients is presented in Figure 12 for all particles' concentrations and size fractions. 
a)
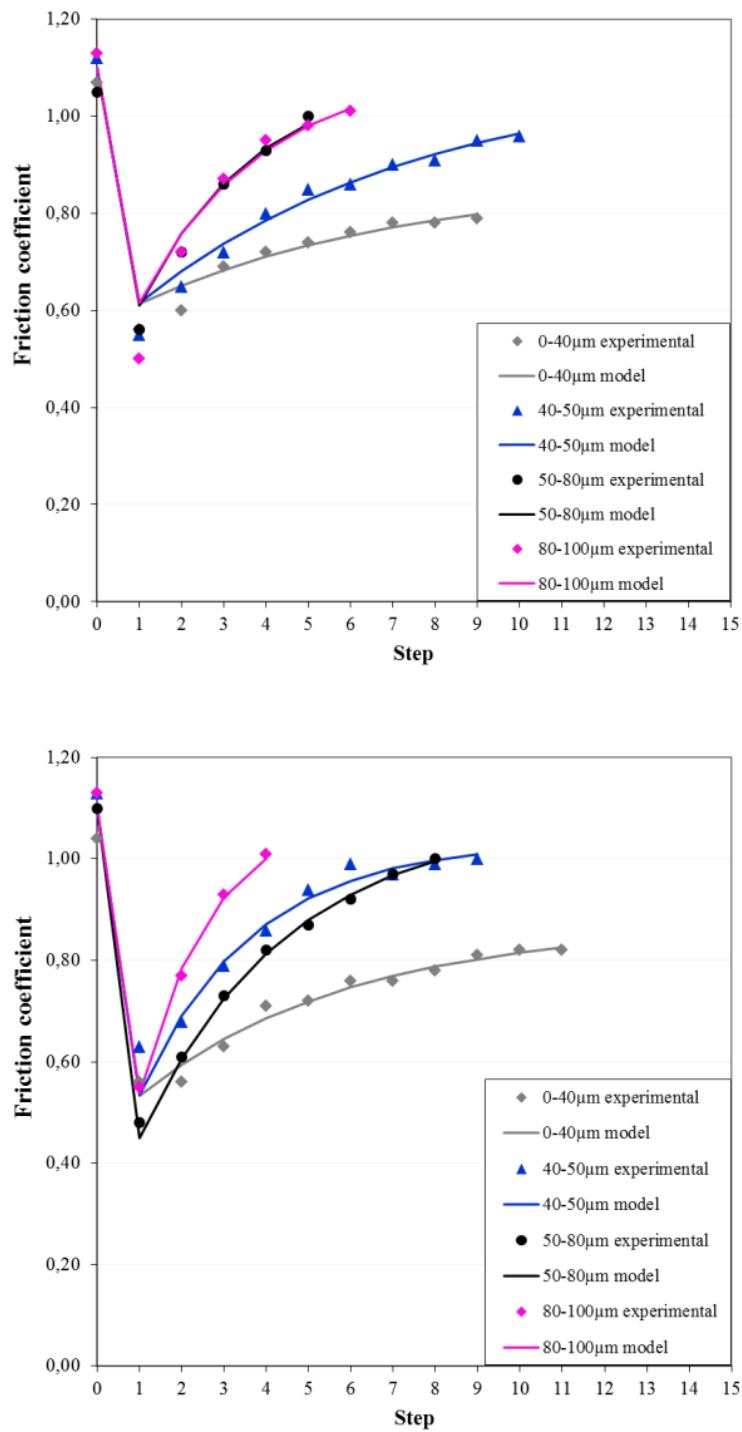

b)

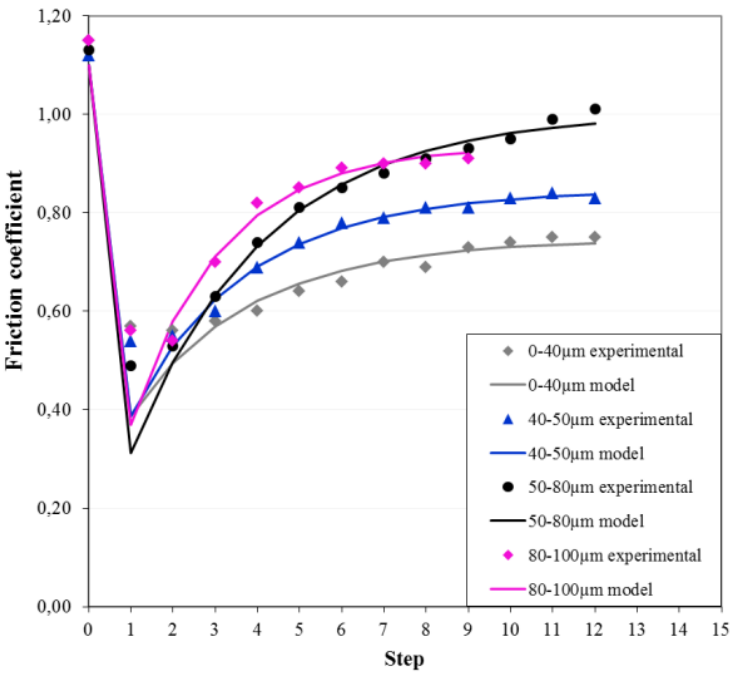

c)

Fig.12 Comparison of calculated and measured friction coefficients (Particles concentration a: $10 \mathrm{~g} / \mathrm{m} 2 ; \mathrm{b}: 20 \mathrm{~g} / \mathrm{m} 2 ; \mathrm{c}: 40 \mathrm{~g} / \mathrm{m} 2)$ 
It can be seen that the proposed model, combining equations (1) and (7), is able to describe the frictional behavior of the contaminated surfaces. Despite some scatters at step 1, which may be due to the determination of $\mathrm{X}_{1}$ or $\mu_{\text {film }}$, the agreement between the model and the experiment is satisfactory for all test configurations.

Figure 13 shows two examples of terms $X . \mu_{\text {film }}$ and $(1-X) \cdot \mu_{\text {surface }}$ (the clean state is not shown).

a)
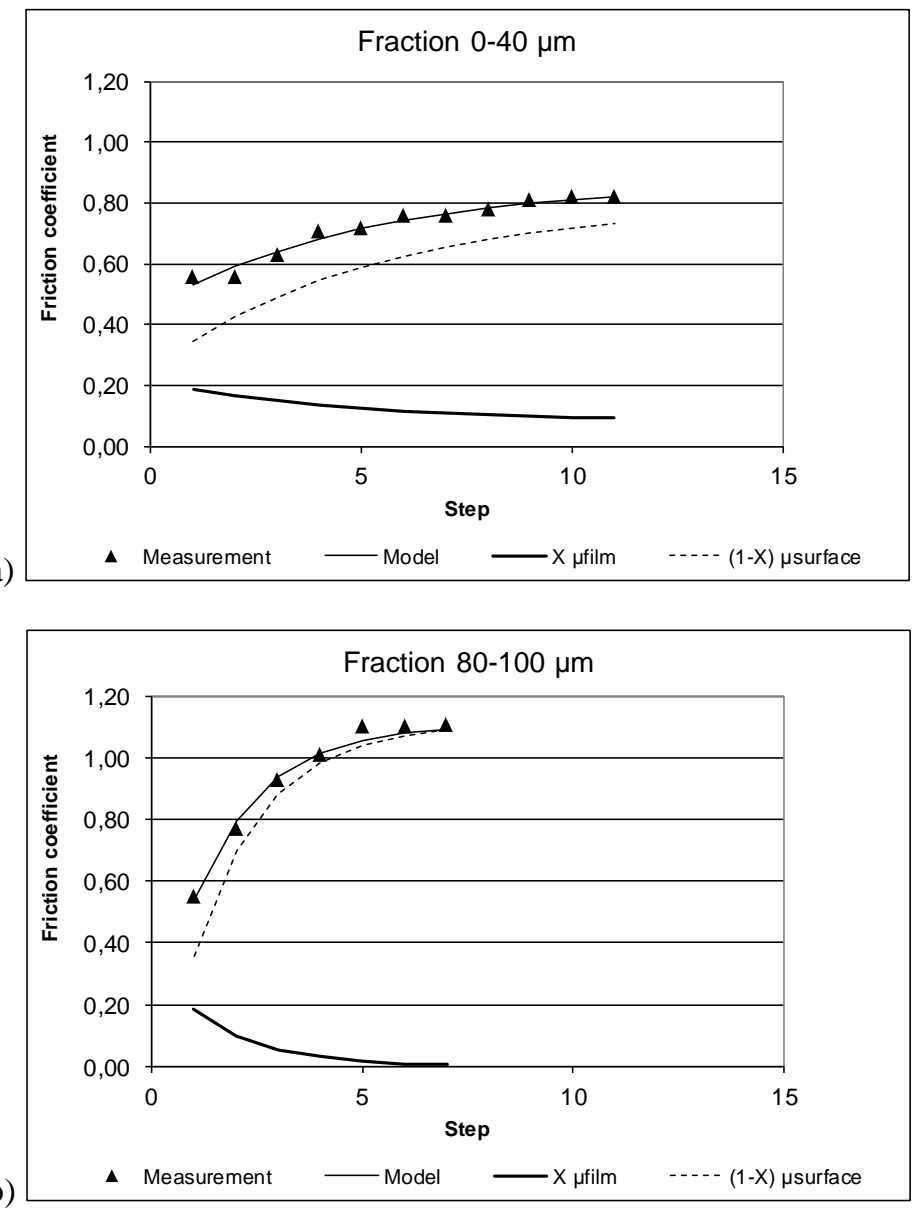

Fig.13 Friction and $\mu_{\text {film }}$ and $\mu_{\text {surface }}$ components (a: fraction $0-40 \mu \mathrm{m}$; b) fraction 80 $100 \mu \mathrm{m})$

It can be seen that the friction component related to the film of particles decreases with the number of passages while the component bound to the surface increases. This observation corroborates what is observed during the friction tests and quantified by the analysis of the mass of the particles in [2], namely, the quantity of particles present on the surface, which is related to the $\mu_{\text {film }}$ component, decreases with the passages of the SRT pad. The size of the particles has an impact on the evolution of the two terms of friction. On the $0-40 \mu \mathrm{m}$ fraction (Figure 13a), the two terms evolve progressively, corroborating the observations with the GoPro camera which show a gradual removal of particles (Figure $7 \mathrm{a}, \mathrm{b}$ and $\mathrm{c}$ ). We also see that the term X. $\mu_{\text {film }}$ does not cancel out 
(within the limits of the studied passages) and reflects well the effect of the trapping of fine-fraction particles, which therefore continue to lubricate the interface between the pad and the surface. On the fraction $80-100 \mu \mathrm{m}$, the term $(1-\mathrm{X}) . \mu_{\text {surface }}$ grows very quickly and the term X. $\mu_{\text {film }}$ quickly reaches the null value (Figure 13b). In addition, it can be seen that the overall friction depends essentially on the component related to the surface. The model therefore translates a very rapid ejection of coarse particles and, as a result, the surface becomes clean after few passes of the SRT pad. Again, these properties corroborate visual observations with high-speed cameras (Figure $7 \mathrm{~d}$, e and $\mathrm{f}$ ).

\subsubsection{Variation of the modelled surface coverage}

Values of ratios $\alpha$ and $\lambda$, as well as $X_{1}$ are presented in Table 3 .

Table 3 Parameters of the coverage and friction models

\begin{tabular}{|c|c|c|c|c|}
\hline Concentration & Size fraction & $X_{1}$ & $\alpha$ & $\lambda$ \\
\hline \multirow{4}{*}{$10 \mathrm{~g} / \mathrm{m}^{2}$} & $0-40 \mu \mathrm{m}$ & 0.587 & 0.041 & 0.889 \\
\hline & $40-50 \mu \mathrm{m}$ & 0.583 & 0.002 & 0.863 \\
\hline & $50-80 \mu \mathrm{m}$ & 0.589 & 0.000 & 0.697 \\
\hline & $80-100 \mu \mathrm{m}$ & 0.583 & 0.000 & 0.705 \\
\hline \multirow{4}{*}{$20 \mathrm{~g} / \mathrm{m}^{2}$} & $0-40 \mu \mathrm{m}$ & 0.682 & 0.050 & 0.862 \\
\hline & $40-50 \mu \mathrm{m}$ & 0.681 & 0.025 & 0.705 \\
\hline & $50-80 \mu \mathrm{m}$ & 0.783 & 0.006 & 0.756 \\
\hline & $80-100 \mu \mathrm{m}$ & 0.677 & 0.000 & 0.560 \\
\hline \multirow{4}{*}{$40 \mathrm{~g} / \mathrm{m}^{2}$} & $0-40 \mu \mathrm{m}$ & 0.922 & 0.173 & 0.882 \\
\hline & $40-50 \mu \mathrm{m}$ & 0.922 & 0.143 & 0.856 \\
\hline & $50-80 \mu \mathrm{m}$ & 0.950 & 0.031 & 0.755 \\
\hline & $80-100 \mu \mathrm{m}$ & 0.891 & 0.074 & 0.680 \\
\hline
\end{tabular}

Figure 14a and Figure 14b show the variations with the particles' concentrations and sizes of the parameters $\lambda$ and $\alpha$ respectively. It should be noted that because the adjustments are made for all protocol steps, the model implicitly assumes that $\lambda$ and $\alpha$ remain constant during a test series. 


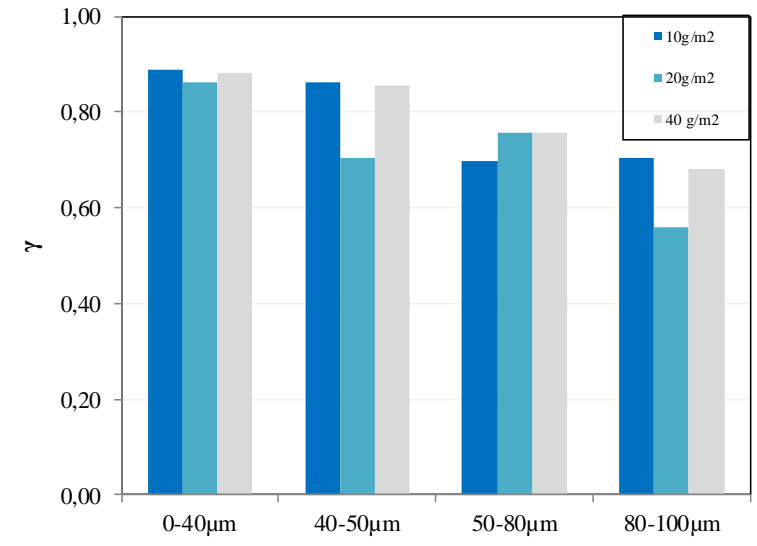

a) Size fraction $(\mu \mathrm{m})$

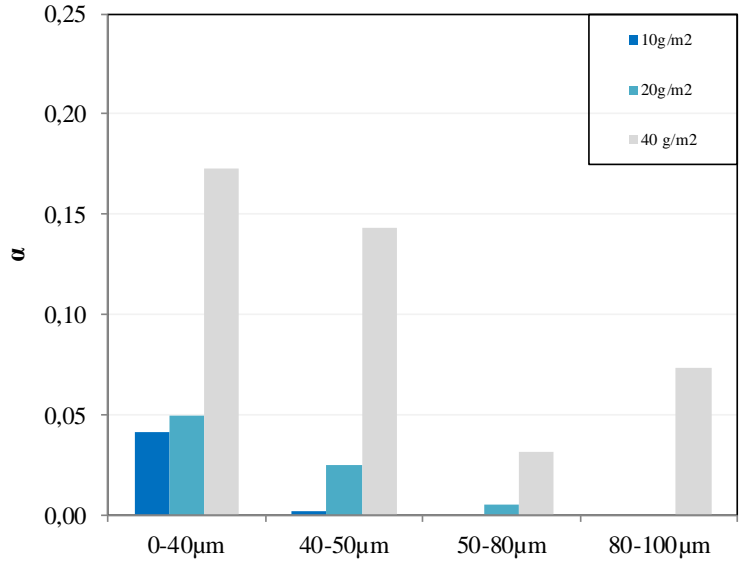

b)

Fig.14 Variations of (a) $\gamma$ and (b) $\alpha$ with particles' concentration and size fraction

Figure 14a shows that the ejection ratio decreases as particle size increases. According to the visual observations presented in section 5 , the particles of the fractions $0-40 \mu \mathrm{m}$ and $40-50 \mu \mathrm{m}$ are ejected at all stages and, for particles of the $80-100 \mu \mathrm{m}$ fraction, ejection is important in step 1 and does not exist in the following steps (steps 1 to 3 observed, Figure 7). On average, the ejection of the particles of the fractions $0-40 \mu \mathrm{m}$ and 40 $50 \mu \mathrm{m}$ is therefore greater than that of the particles of the fractions $50-80 \mu \mathrm{m}$ and $80-100 \mu \mathrm{m}$.

Figure $14 \mathrm{~b}$ shows that the recirculation ratio is higher when the particle size is smaller and when the initial concentration of the particles is larger. Regarding the size of the particles, it can be assumed that the more they are fine, the more their dispersion will be facilitated inducing a greater surface coverage (the side-views provided by high-speed cameras do not allow to visualize this phenomenon). Regarding the concentration, one can imagine that a larger amount of particles induces a proportional amount of particles raised and dropped on the surface, resulting in a higher recirculation ratio.

The variation of the surface coverage fraction with the contamination steps is shown in Figure 15. 


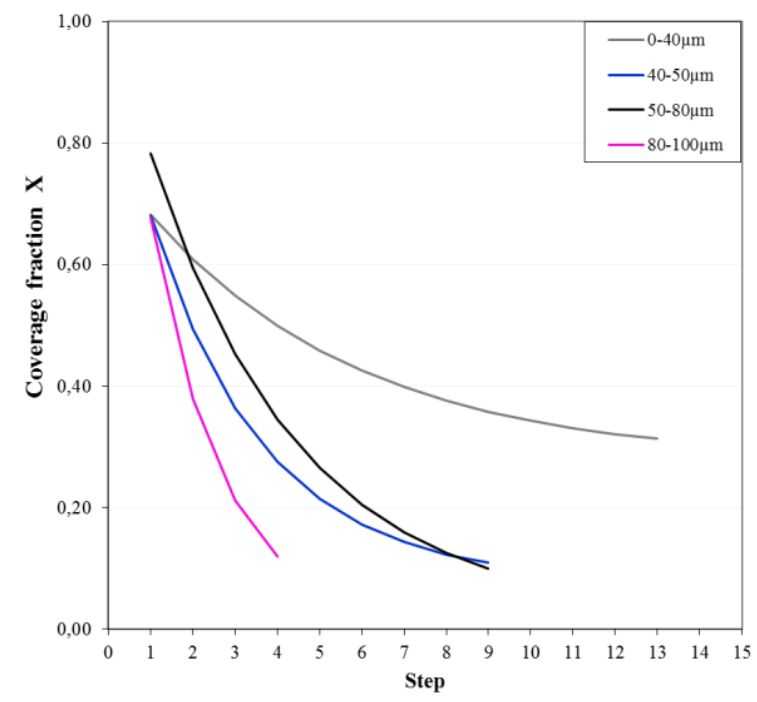

Fig.15 Variation of the surface coverage with the contamination steps (Concentration of $20 \mathrm{~g} / \mathrm{m} 2)$

Fraction $0-40 \mu \mathrm{m}$ induces a coverage fraction which decreases slowly with the SRT pad's passes and stabilizes at a high level at the end of the test (above 0.3); in contrast, the surface coverage decreases rapidly for fraction $80-100 \mu \mathrm{m}$ and reaches lower level at the end of the test. The variation of the surface coverage shows a logical hierarchy with respect to particle size and corroborates the observations made in previous sections. Actually, as fine particles are more easily trapped by the surface voids and would be more dispersed when they are raised by the SRT pad, they continue to cover the surface and, as a matter of fact, contribute to both the low decrease and the high values of the surface coverage. The rapid decrease and the low values of the surface coverage for coarse particles can be explained in the same way based on the rapid ejection of these particles.

Figure 16 shows the evolution of the surface coverage as a function of the mass of particles. All size fractions are presented in the same figure for the three particle concentrations. 


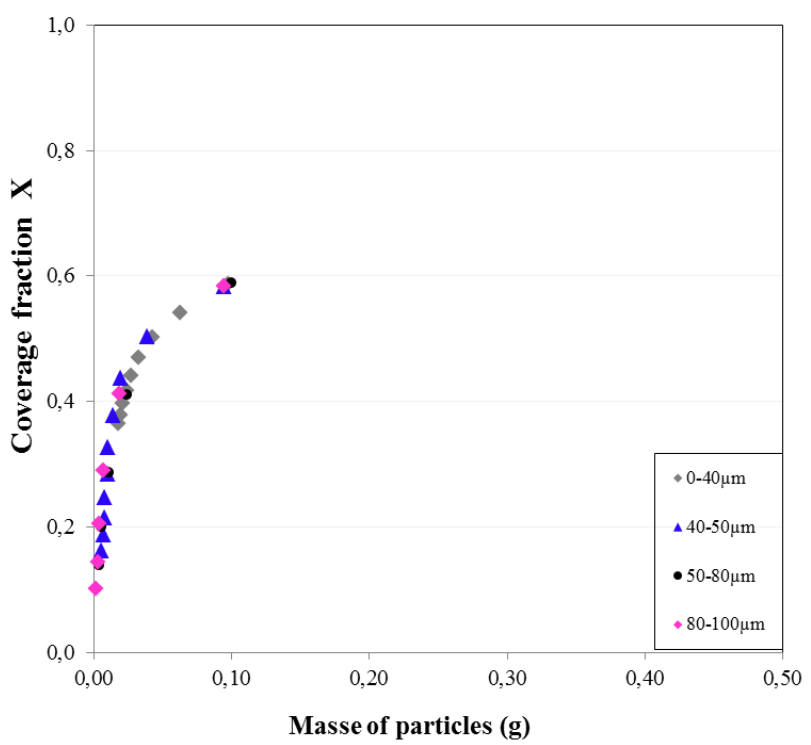

a)

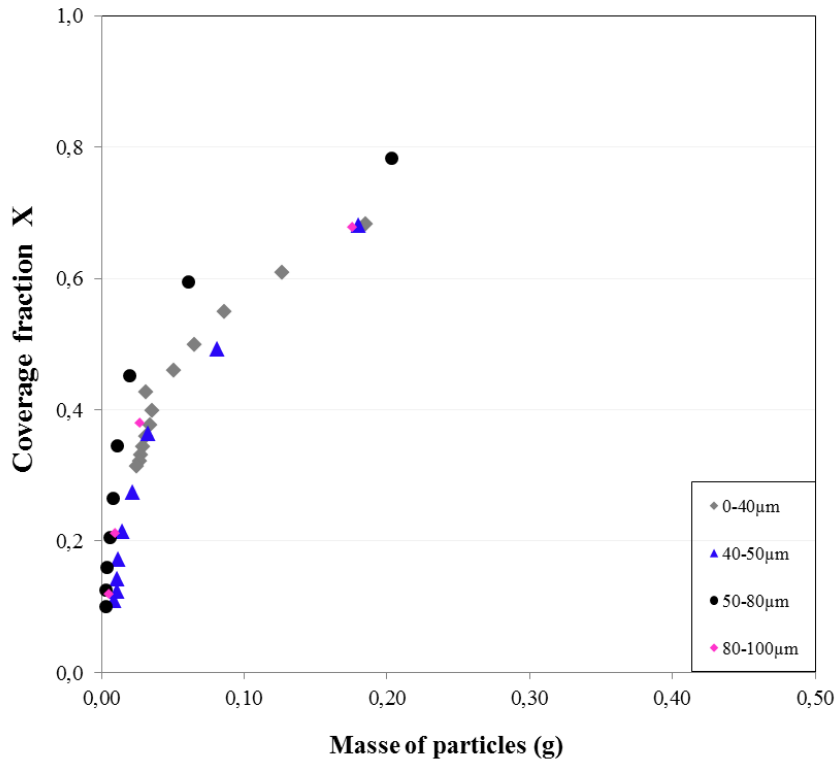

b) 


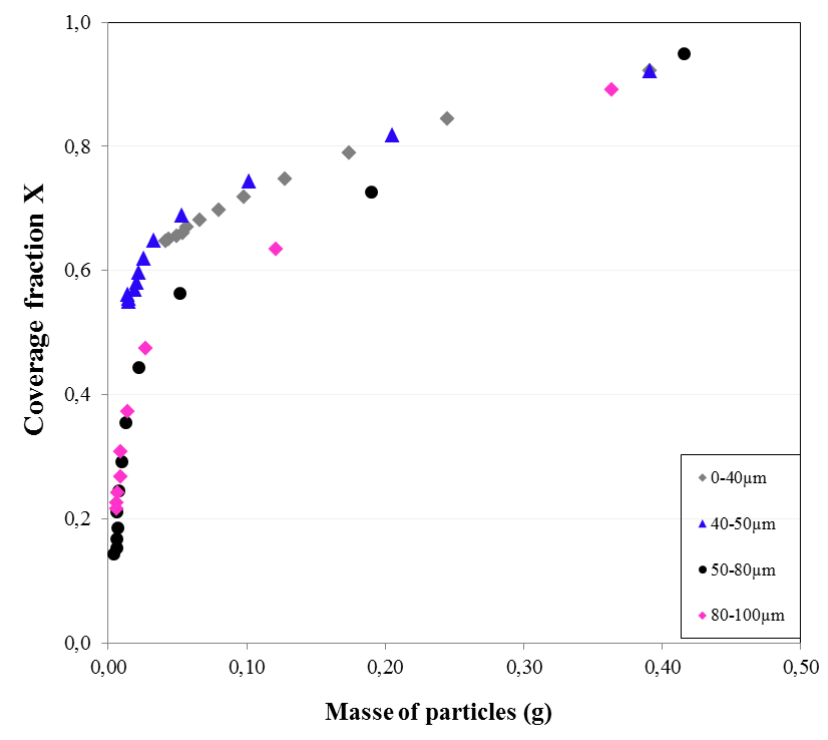

c)

Fig.16 Surface coverage as a function of the mass of particles (Concentrations a: $10 \mathrm{~g} / \mathrm{m} 2$; b: $20 \mathrm{~g} / \mathrm{m} 2 ; \mathrm{c}: 40 \mathrm{~g} / \mathrm{m} 2$ )

According to the model, the surface coverage does not follow a linear evolution with the mass of the particles: for masses lower than $0.05 \mathrm{~g}$ approximately, the surface coverage increases rapidly; for higher masses, the surface coverage continues to increase but less rapidly. The threshold of $0.05 \mathrm{~g}$ (determined with the naked eye) can be refined by calculating the mass of particles from the void volume in surface valleys $\left(\mathrm{V}_{\mathrm{vv}}\right)$ (see Table 1 in 4.1 ) and the particle density; it gives exactly $0.046 \mathrm{~g}$. The surface coverage for small masses of particles (at the end of a series of tests) would therefore correspond to a filling of the surface valleys.

When all valleys are filled, the surface coverage depends on the characteristics of the particles. Indeed, it is observed that for the concentrations $10 \mathrm{~g} / \mathrm{m} 2$ and $20 \mathrm{~g} / \mathrm{m} 2$, the surface coverage follows a master curve for all particle sizes. For the concentration $40 \mathrm{~g} / \mathrm{m} 2$, some scatters are observed. There is thus a limit concentration below which the particles fill the voids of the surface regardless of their size. This limit would correspond to the filling of the volumes $\mathrm{V}_{\mathrm{vv}}+\mathrm{V}_{\mathrm{vc}}$ (see Table 1 in 4.1); the corresponding limit mass of particles is $0.443 \mathrm{~g}$. For larger quantities, the particles are not blocked by the surface voids and their distribution would depend on many parameters such as their sizes and shapes, their weights, and so on. At concentration $40 \mathrm{~g} / \mathrm{m} 2$, one can see that, for the same mass, the fractions $0-40 \mu \mathrm{m}$ and $40-50 \mu \mathrm{m}$ cover more surface than the fractions $50-80 \mu \mathrm{m}$ and 80 $100 \mu \mathrm{m}$ (Figure 16c). This trend would be logical if one considers that, for the same mass, there are more fine particles thus more possibilities of coverage and moreover, the fine particles are more easily raised by the passage of the SRT pad and their dispersion in the air would give higher surface coverage. 


\section{Conclusions}

This paper presents an analytical model expressing the coverage of a road surface contaminated by fine particles. The research methodology is based on the identification of particles' flows in the tire/road interface by means of high-speed cameras. Visualization of the passages of a rubber pad sliding on a textured surface, which simulates the road surface microtexture, covered by particles at different concentrations and sizes reveals an ejection flow and a recirculation flow composed of particles raised by the rubber pad then fall back to the surface. By establishing a parallel between the mechanisms of ejection and recirculation of the particles and the mechanisms of adsorption and removal of gaseous contaminants, an analytical model of the literature has been transposed for the calculation of the surface coverage by particles based on two parameters called respectively the ejection and recirculation ratios.

Interpretation of the surface coverage values, even though they cannot be measured, supports statements made in previous studies on the mechanism of trapping of the particles. In the meantime, it also provides quantitative information on this mechanism mainly in terms of the interaction between the particles' size and the surface texture (void volumes in the core and the valleys). Application of the coverage model to the calculation of friction (linear rule-of-mixtures equation) provides satisfactory comparison with friction data obtained from tests conducted in laboratory. Interpretation of the results helps to better understand the effect of the particles' characteristics (concentration and size) on the sharing of load support between the surface's and particle layer's components.

To transpose the developed model to road surfaces, there is a need to not only test actual road surfaces but also evaluate the effect of other factors such as the composition of the particles. In the present paper, particles are composed mainly of quartz whose grains have a rolling / sliding behavior (and scratching as well depending on the radius of curvature of the grains [17]). It has been found in a separate study [17] that the adhesive behavior of clay induces a bonding of the particles to the substrate and, as a matter of fact, has a lasting effect on friction. The consideration of clay, and more generally organic matters which were eliminated by the drying process of the sediments in the present study, will also emphasize the nature of the substrate due to the fact that friction results from both mechanical and chemical interactions at the tire/road interface.

\section{Acknowledgment}

The authors thank Patrick Maisonneuve, Christophe Ropert and Jean-François Le Fur for the realization of all experiments. We also thank Simon Changarnier for his work on the development of the test set-up with the high- 
speed camera.

\section{References}

[1] D. Eisenberg, The mixed effects of precipitation on traffic crashes. Accident Analysis and Prevention, 36, 637-647, 2004.

[2] Y. Hichri, V. Cerezo, MT. Do, Effect of dry deposited particles on the tire/road friction. Wear, 376-377, 1437-1449, 2017.

[3] C.F. Higgs, E.Y.A. Wornyoh, An in situ mechanism for self-replenishing powder transfer films: Experiments and modeling. Wear, 264, 131-138, 2008.

[4] H. Heshmat, Wear reduction systems for coal-fueled diesel engines - Experimental results and hydrodynamic model of powder lubrication. Wear, 162-164, 518-528, 1993.

[5] IC. Faraon, Mixed lubricated line contacts. Ph.D. Thesis, University of Twente, Enschede, The Netherlands, 2005.

[6] KL. Johnson, JA. Greenwood, SY. Poon, A simple theory of asperity contact in elasto-hydrodynamic lubrication. Wear, 19, 91-108, 1972.

[7] JA. Greenwood, JBP. Williamson, Contact of nominally flat surfaces. Proceedings of the Royal Society of London. Series A, Mathematical and Physical Sciences, 295(1442), 300-319, 1966.

[8] K.A. Grosch, The relation between the friction and visco-elastic properties of rubber, Proceedings of the Royal Society of London, Series A, Mathematical and Physical Sciences, 274(1356), 21-39, 1963.

[9] B. N. J. Persson, U. Tartaglino, O. Albohr, and E. Tosatti, Rubber friction on wet and dry road surfaces: the sealing effect. Physical Review, B71, DOI: 10.1103/PhysRevB.71.035428, 2005.

[10] R. Mills, R.S. Dwyer-Joyce, M. Loo-Morrey, The mechanisms of pedestrian slip on flooring contaminated with solid particles. Tribology International, 42, 403-412, 2009.

[11] TA. Blanchet, WG. Sawyer, Differential application of wear models to fractional thin films. Wear, 251, 1003-1008, 2001.

[12] WG. Sawyer, PL. Dickrell, A fractional coverage model for gas-surface interaction in reciprocating sliding contacts. Wear, 256, 73-80, 2004.

[13] I. Langmuir, The constitution and fundamental properties of solids and liquids - Part 1: Solids. J. Am. Chem. Soc., 38 (11), pp 2221-2295, 1916. 
[14] PL. Dickrell, WG. Sawyer, A. Erdemir, Fractional coverage model for the adsorption and removal of gas species and application to superlow friction diamond-like carbon. Tribology, 126, 615-619, 2004.

[15] JA. Heimberg, KJ. Wahl, IL. Singer, A. Erdemir, Superlow friction behavior of diamond-like carbon coatings: Time and speed effects. Applied Physics Letters, 78(17), 2449-2451, 2001.

[16] S. Descartes, Y. Berthier, Rheology and flows of solid third bodies: Background and application to a $\mathrm{MoS}_{1.6}$ coating. Wear, 252, 546-556, 2002.

[17] S. Changarnier, Y. Hichri, V. Cerezo, MT. Do, F. Salvatore, H. Zahouani, Observations of dry particles behaviour at the tyre/road interface. Tribol. Int., 128, 291-301, 2018.

[18] RB. Shakely, JJ. Henry, RJ. Heinsohn, Effects of pavement contaminants on skid resistance. Transportation Research Record, 788, 23-28, 1980.

[19] R. Danzl, F. Helmli and S. Scherer, Focus variation - A robust technology for high resolution optical 3D surface metrology. J. Mechanical Engineering, 57(3), 245-256, 2011.

[20] NF EN 1097-7, Tests for mechanical and physical properties of aggregates — Part 7: Determination of the particle density of filler — Pyknometer method, 2008.

[21] C. Wang, MA. Quddus, SG. Ison, The effect of traffic and road characteristics on road safety: A review and future research direction. Saf. Sci. 57, 264-275, 2013.

[22] Y. Hichri, V. Cerezo, MT. Do, Friction on road surfaces contaminated by fine particles: Some new experimental evidences. J. Eng. Tribol. 231(9), 1209-1225, 2017. 
Materials 2019

Elsevier Editorial System(tm) for Wear of

Manuscript Draft

Manuscript Number: WOM2019-D-18-00103R1

Title: Modeling of the surface coverage and application to the calculation of friction on surfaces contaminated by particles

Article Type: Case Study / Test Methods

Keywords: Particles; Surface coverage; Third body flow; Friction

Corresponding Author: Dr. Minh-Tan Do, PhD

Corresponding Author's Institution: IFSTTAR

First Author: Yosra Hichri

Order of Authors: Yosra Hichri; Veronique Cerezo; Minh-Tan Do, PhD

Abstract: This paper deals with the modeling of the coverage of surfaces contaminated by fine particles, the objective being the prediction of the skid resistance of road surfaces when it rains after a long dry period. The research methodology is based on the identification of particles' flows in the tribological circuit composed of the particles (3rd body) and the tire and the road (1st bodies). Experiments are conducted in laboratory where sliding friction is measured between a rubber pad (simulating a tire tread block) and a sandblasted aluminum surface (simulating a microtextured road surface) covered by particles. The test program includes particle concentrations representative of deposits of particles on the road surface at different dry periods and different particle size fractions. The test protocol consists in repeating passages of a rubber pad on the test surface and visualizing the particles' movements by means of high-speed cameras. Two particles' flows are identified: particles ejected from the contact and those raised by the rubber pad then fall back to the surface. Similarities are established with the removal and deposition of gas species in vapor-phase lubrication. An analytical model was derived to express the surface coverage as a function of the number of passages and two parameters (values between 0 and 1 ) called respectively the ejection and recirculation ratios. The proposed model is included in a linear rule-ofmixtures equation for the calculation of friction. Calculated friction coefficients compare favorably to experimental data and the model's parameters are determined. A master curve for different particles' sizes is obtained when relating the surface coverage to the mass of particles. Relationships between the ejection and recirculation ratios, the particles' characteristics and the surface texture are presented. Discussions are made in terms of transposition of the model to real road surfaces. 


\section{WEAR}

\section{Confirmation of Authorship}

\section{Please save a copy of this MS Word file, complete and upload as the "Confirmation of Authorship" file.}

As corresponding author, I Minh-Tan Do, hereby confirm on behalf of all authors that:

1) The authors have obtained the necessary authority for publication.

2) The paper has not been published previously, that it is not under consideration for publication elsewhere, and that if accepted it will not be published elsewhere in the same form, in English or in any other language, without the written consent of the publisher.

3) The paper does not contain material which has been published previously, by the current authors or by others, of which the source is not explicitly cited in the paper.

Upon acceptance of an article by the journal, the author(s) will be asked to transfer the copyright of the article to the publisher. This transfer will ensure the widest possible dissemination of information. 
Article: Modeling of the surface coverage and application to the calculation of friction on surfaces contaminated by particles (WOM2019-D-18-00103)

Authors: Yosra Hichri, Veronique Cerezo, Minh-Tan Do

Corresponding author: Minh-Tan Do (minh-tan.do@ifsttar.fr)

\section{Responses to the Reviewer 1}

Thank you very much for your valuable comments and suggestions. We have copied and pasted your comments below and divided them into sections. Our responses to each comment are in blue. In addition, the modified or added text is highlighted in the article.

Reviewers' comments:

Overview

1) The work is interesting and the agreement between experiments and model is encouraging but is this study that relevant to real road surfaces? Firstly, the authors use an aluminium plate rather than the materuials used in a real road surface such as aggregate or concrete, so the relevance of using aluminium is rather suspect.

We have provided a justification of the use of aluminum in the study. Actually, this material has been chosen because the test protocol requires weighing of the test sample before and after friction measurements to determine the mass of particles (results are reported in a paper published in the Special Issue of WOM 2017) and road samples are too heavy for the precision scale used in the study. Moreover, as the study is primarily focused on mechanical interactions (void filling, rolling and sliding, etc.) between the particles and the road surface asperities, emphasis is given first to the reproduction of the surface microtexture.

Also, the authors state that the macrofinish of the wheel ( and presumably the road surface) is not taken into account. How sound is this simplication?

- This simplification is justified by the fact that the contamination by particles (dust and traffic debris) affects mainly the road surface microtexture by filling the small asperities; a reference from the literature has been added ( $\left.n^{\circ} 18\right)$. The surface macrotexture can be then neglected without compromising the studied phenomenon.

- We also added a justification in section 4.3 for the use of a rubber block without grooves: as the friction loss due to particles occurs at low slip speeds (from reference 18), tire grooves have a negligible effect and the use of a rubber block with no groove to simulate the tire friction does not bias the studied phenomenon.

2) Along the same lines, how does the stiffness of the substrate affect the results? Does the composition of the particles affect the results, and in any case what is their composition and where do they come from.

- The origin and the chemical composition of the particles have been added. 
- The stiffness of the substrate should theoretically affect the results. However, compared with the rubber hardness, stiffness of aluminum and asphalt concrete are high enough to be considered as similar.

- Comments on the effect of the composition of the particles have been added in the conclusions of the paper.

3) What is the mechanism that causes the particles to spring into the air as the rubber pad passes over the particles? It is presumably linked to the elasticity of the rubber pad.

An explanation has been provided in section 5.2 (between figures 8 and 9).

4) The contrast in figures 6 and 7 is not good and needs to be improved.

- The contrast of the images has been increased. The images have been enlarged and other indications provided (arrows, dotted lines) to give an idea about the size of the particles' clouds after successive passages of the rubber pad.

- Images were extracted from VLC video player and it is not easy to obtain better resolutions.

5) There are no scale markers in any of the micrographs reported in the paper. This need to be added.

- In figure 9, the length of the images is indicated. It is calculated from the total number of pixels (1280) and the size of each pixel $(12 \mu \mathrm{m})$.

- The coordinates of each particle are calculated from the origin located at the upper left corner of the images.

6) For the measurements of particle velocimetry in Figure 9, clear identification of the particles is required.

- Images are provided with the position of the three particles tracked for each size fraction.

- Actually, the first calculations were made by the first author who has left the institute. Unfortunately, only the calculated speeds are left without any identification of the particles used for the calculations. We had to redo the analysis and, even if the mean value of the particles' speed remain similar as well as the hierarchy between the size fractions, the scatter is higher than what had been reported in the first version of the paper. Nevertheless, we prefer to report the updated results in the revised version.

- As a consequence of the higher scatter in the updated results, the observation about the orientation of the red arrows in figure 9 (the smaller is the particle size, the steeper is the arrow) reported in the first version is no more valid. This observation has been removed in the revised version.

From the paper it would seem that there is some uncertainty in this. The confidence in the measurements could be increased if a shorter time between frames was used.

We have tried to estimate the speed from two successive frames. The scatter is unchanged as well as the mean value. So we have calculated the speed from at least 5 frames (the maximum number of frames considered is 10). 
7) It might be useful to add a time sequence of images for one test into the paper to show the dynamics of the process in more detail.

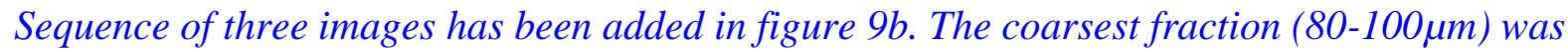
chosen to facilitate the visualization. The dotted line corresponds to the position of the studied particle in the first image. The arrows show not only the position of the same particle in the following images, relative to its position in the first image, but also the trajectory and the speed (because the speed is calculated from the position and the elapsed time).

8) The word cartographies is used in the paper. I think the term topographical maps or simply topography is a better term.

Thank you for the suggestion. Modifications are done and highlighted in the text.

9) Overall I think the title does not really reflect the content in that the model described in the paper although relevant would not be able to calculate the friction of roads without a lot more work. I suggest that the word roads is removed from the title and the application to roads is emphasised in the abstract / introduction.

Thank you for the suggestion. Modifications are done and highlighted in the text. 
Article: Modeling of the surface coverage and application to the calculation of friction on road surfaces contaminated by particles

Authors: Yosra Hichri, Veronique Cerezo, Minh-Tan Do

Corresponding author: Minh-Tan Do (minh-tan.do@ifsttar.fr)

\section{Highlights}

- Particles as a third body in the tire/road interface.

- High-speed cameras to visualize and identify the particles' flows.

- Parallel with the removal and deposition of gaseous contaminants in vapor-phase lubrication.

- Analytical model to predict the surface coverage and friction.

- Results from the model corroborate visual observations and physical mechanisms. 